\title{
Analysis of House Prices to Assess Economic Impacts of New Public Transport Infrastructure Madrid Metro Line 12
}

\author{
Lucia Mejia Dorantes, Antonio Paez, and Jose Manuel Vassallo
}

\begin{abstract}
Transportation infrastructure is known to affect the value of real estate property by virtue of changes in accessibility. The impact of transportation facilities is highly localized as well, and it is possible that spillover effects result from the capitalization of accessibility. The objective of this study was to review the theoretical background related to spatial hedonic models and the opportunities that they provided to evaluate the effect of new transportation infrastructure. An empirical case study is presented: the Madrid Metro Line 12, known as Metrosur, in the region of Madrid, Spain. The effect of proximity to metro stations on housing prices was evaluated. The analysis took into account a host of variables, including structure, location, and neighborhood and made use of three modeling approaches: linear regression estimation with ordinary least squares, spatial error, and spatial lag. The results indicated that better accessibility to Metrosur stations had a positive impact on real estate values and that the effect was marked in cases in which a house was for sale. The results also showed the presence of submarkets, which were well defined by geographic boundaries, and transport fares, which implied that the economic benefits differed across municipalities.
\end{abstract}

Public transportation infrastructure is known to affect urban areas in a number of significant ways. The effects of public transportation were classified by Banister and Berechman (1) as follows: transportationrelated effects, land use effects, and effects on jobs and business activities. Researchers, including Mas and Maudos, have shown that transportation infrastructure has significant, direct effects that also tend to spill over in the form of neighborhood effects (2). According to Boarnet (3), these effects can be classified as short term (i.e., related to reductions in travel time for the population that lives or works around the infrastructure), and long term [i.e., that stem from agglomeration economies caused by positive externalities that improve the efficiency of firms as the result of economies of scale (4)].

Commuter rail and metro stations can have both positive (e.g., accessibility benefits) and negative (e.g., noise and congestion)

L. M. Dorantes and J. M. Vassallo, Departamento de Transportes, Universidad Politecnica de Madrid, ETSI de Caminos, Canales y Puertos, Profesor Aranguren s/n, 28040 Madrid, Spain. A. Paez, School of Geography and Earth Sciences, McMaster University, General Science Building, Room 236, 1280 Main Street West, Hamilton Ontario L8S 4L8, Canada. Corresponding author: L. M. Dorantes, Imejia@caminos. upm.es. effects. On the positive side, metro stations increase accessibility to public transportation for the people that live nearby and reduce their travel time and costs to other destinations in urban areas, which produces a network externality. Similarly, business activities near the stations enjoy advantages. Jobs and shops are accessible to those that come from any destination. Business activities close to the stations-especially shops-benefit from the increase in passersby to and from the stations. Many of the negative effects associated with metro stations are spatial externalities, which include noise and changes to the urban landscape. The effects described above depend on the type of transport infrastructure (2, 5), its location, and its specific characteristics. Researchers such as Maoh et al. have noted a strong interdependence between the locational patterns among residential and commercial land development ( 6 ).

A problem of interest that arises whenever new transportation infrastructure, services, or both, are introduced is how to assess the net impact of the positive and negative effects. Two methods to assess real estate markets are discussed in the literature: the repeated sales approach and the hedonic price analysis. Hybrid models, which combine those methodologies, also have been used. Bailey et al. first presented repeated sales deals with a regression of the difference in sale prices for the same set of homes and a set of time-of-sale indicators (7). Repeat sales can be difficult to implement as the result of small sample sizes. The sale of each property may be transacted infrequently, and the lengthy periods of time needed to collect a sufficiently large sample can be impractical or impossible in the case of new infrastructure. Compared with hedonic price analysis, repeat sales implementations are relatively rare $(8)$.

The hedonic models refer to the implicit characteristics of a good (9). In the case of real estate, the idea is that property prices can be decomposed to evaluate the price of various structural, locational, and neighborhood characteristics. To estimate the implicit price for each attribute, the price is modeled as a function of various attributes and the use of a linear regression model with parameters estimated by the ordinary least squares (OLS) method. A house unit is fixed in its location and influenced by the characteristics of the neighborhood, which constitute a set of geographically distributed data. Data members may be related to each other as well, which is known as spatial autocorrelation $(10,11)$. Spatial hedonic analysis has emerged as an approach that accounts for spatial autocorrelation in real estate applications.

The literature that accounts for transport effects in land value through different approaches is extensive (12-16). As noted by Martínez and Viegas (17) and Du and Mulley (18), however, studies 
are lacking on the impact of transport infrastructure improvements in Spain, which may reflect the lack of detailed data available. Few detailed Spanish case studies that relate to spatial hedonic models are available, and they do not focus on the relation of transportation and housing (19-21).

The case study presented in this paper was done in the region that surrounds Madrid, Spain, and focused on its five most important southern municipalities, which lacked interconnection through urban mass transportation. To rectify this situation, a metro line (Line 12), known as Metrosur, was built. It is a circle line of about $54.6 \mathrm{~km}$, and it has transfer stations to the commuter rail and metro network to connect with the city of Madrid. The construction of Metrosur began in 2000, and the line started operation in April 2003. By the time the case study began, sufficient time had elapsed to allow evaluation of the economic impact of the public transport infrastructure in the real estate market. To improve the reliability of the model, a spatial econometric analysis was conducted, and the presence of submarkets was assessed through geographic boundaries and transit zonal fares.

This paper is divided into six sections. The second section describes the case study area. The third section presents the theoretical background of hedonic models and spatial analysis. The fourth section describes the methodology and data used. The fifth section presents the results. The sixth section offers some concluding remarks.

\section{STUDY AREA}

This study focused on the five, southern municipalities of the Madrid region that are connected by Metro Line 12, Metrosur. At the time of the study, these municipalities had a total population of about 1 million inhabitants. The total population in the area of Madrid was about 6 million people. The municipalities are a huge economic and social pole, made up of small and medium cities that surround the city of Madrid, which had a population of slightly more than 3 million. The cities are connected to Madrid through both private and public means of transportation.

Figure 1 shows the location of the five municipalities within the Madrid region. The shaded areas represent the city of Madrid. The darkest shaded areas show the central districts, while the areas that are shaded only slightly show the outer districts. Until recently, the metro system did not extend beyond the limits of the city of Madrid to reach other municipalities.

In the past three decades, the municipality of Madrid has constrained new real estate development inside the city substantially, which has led to high real estate prices in the city. In response, some municipalities that surround the city on its outskirts began to promote real estate development to increase the supply of affordable housing. As a consequence, some municipalities, which four decades ago were small towns with little connection to the city of Madrid, became in only a few years satellite cities with large populations. They were now places in which people lived and commuted every day to the city. The most impressive growth occurred in the five municipalities located to the southwest of Madrid (i.e., Alcorcon, Mostoles, Leganes, Getafe, and Fuenlabrada). The growth was remarkable, given the combined population of these municipalities as compared with that of the city of Madrid. Figure 2 shows their growth in income per capita between 2000 and 2007.

The transportation systems in these cities used to focus on their connection to the city of Madrid, both through commuter trains and regional buses. The public transportation networks that linked the municipalities used to be extremely poor.

In response, the regional government of Madrid adopted measures to promote more balanced growth of the municipalities. The measures were intended to foster economic activities through greater accessibility to transportation and through better linkage among the five municipalities that surrounded the city of Madrid. To that end, the government built Line 12 (Metrosur). Built entirely underground to minimize negative environmental impacts, the line extended the metro network beyond the city of Madrid for the first time. Metrosur contains 28 stations. It connects to six commuter rail stations (Cercanias) and to one transfer station on Line 10, which take people to downtown Madrid and on to further locations. Its construction cost about 52.7 million $€ / \mathrm{km}$, including the cost of the trains (about 61 U.S. $\$ / \mathrm{km}$ in 2003) (23).

The Madrid transportation network is divided into fare zones $(A, B 1, B 2, B 3, C 1, C 2, E 1$, and E2). The core of Madrid is located in Zone A, and the municipalities are in different zones. Alcorcon, Getafe,

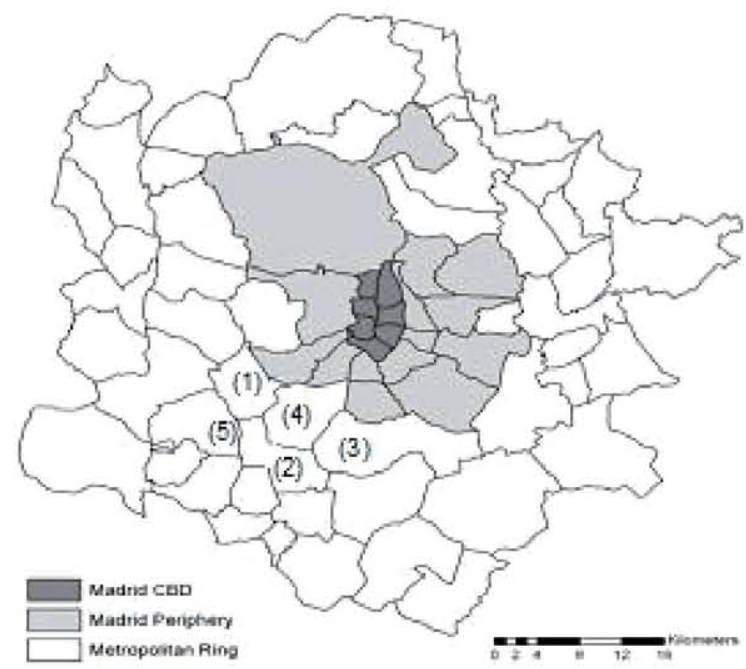

Inhabitants (2009) (22)

$\begin{array}{lr}\text { 1) Alcorcon } & 167,997 \\ \text { 2) Fuenlabrada } & 194,791 \\ \text { 3) Getafe } & 164,043 \\ \text { 4) Leganes } & 184,209 \\ \text { 5) Mostoles } & 206,275 \\ \text { Total } & 917,315\end{array}$

FIGURE 1 City of Madrid districts and surrounding municipalities (22); of five municipalities, Fuenlabrada and Mostoles are located farthest from Madrid. 


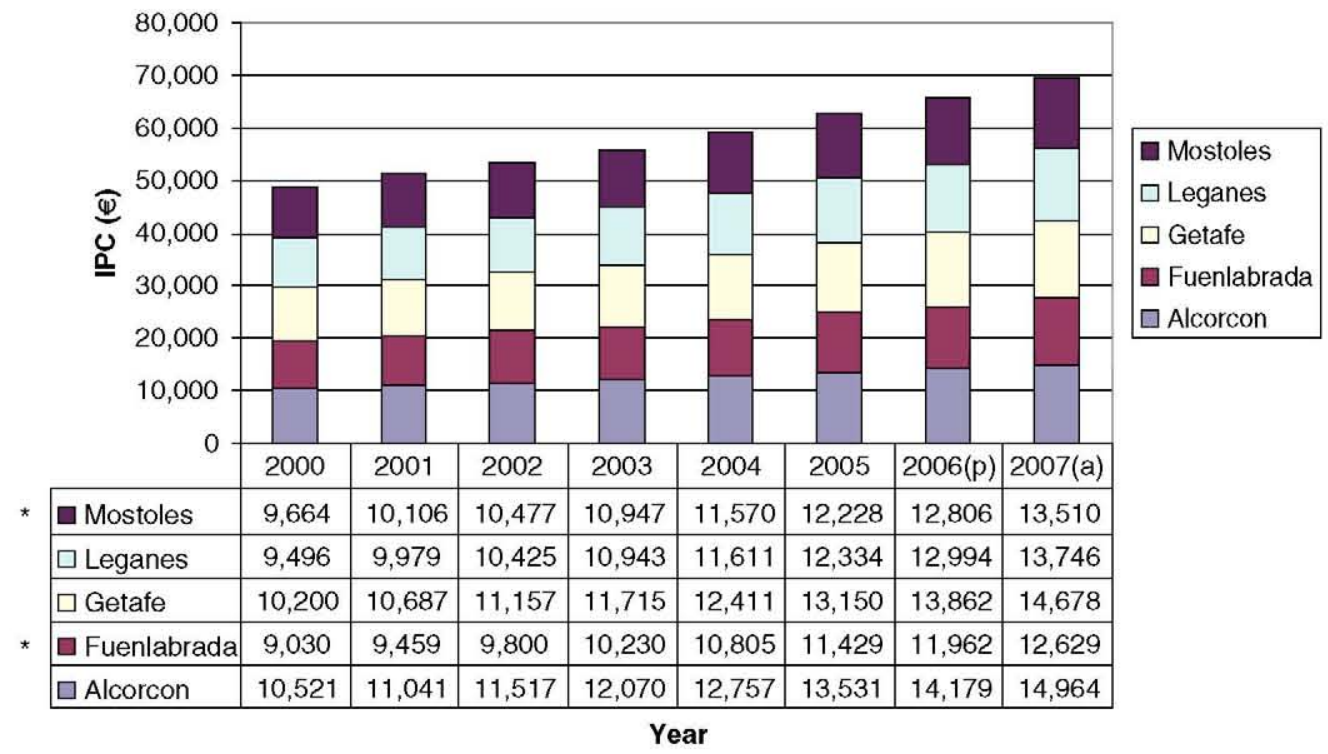

FIGURE 2 Income per capita per municipality (22); of five municipalities, Fuenlabrada and Mostoles have the lowest income per capita.

and Leganes, for example, are located in B1, while Fuenlabrada and Mostoles are located in B2. The farther the location is from the core of Madrid, the more expensive the ticket fare becomes (Figure 3).

Every 8 years the Madrid Transport Authority carries out a household mobility survey. Unfortunately, the last survey available was done in 2004, a year after Metrosur started operation. Another challenge in the analysis of the metro line related to the multiple levels of authority involved: the region of Madrid, five municipalities, and the Madrid Transport Authority. Information was limited about the socioeconomic characteristics of the area. Through an analysis of the household surveys, however, Jordá pointed out that car trips predominated in the metropolitan ring (in which the five municipalities are located) and that this value had increased at a rapid pace: by almost $50 \%$ between 1996 and 2004 (24).

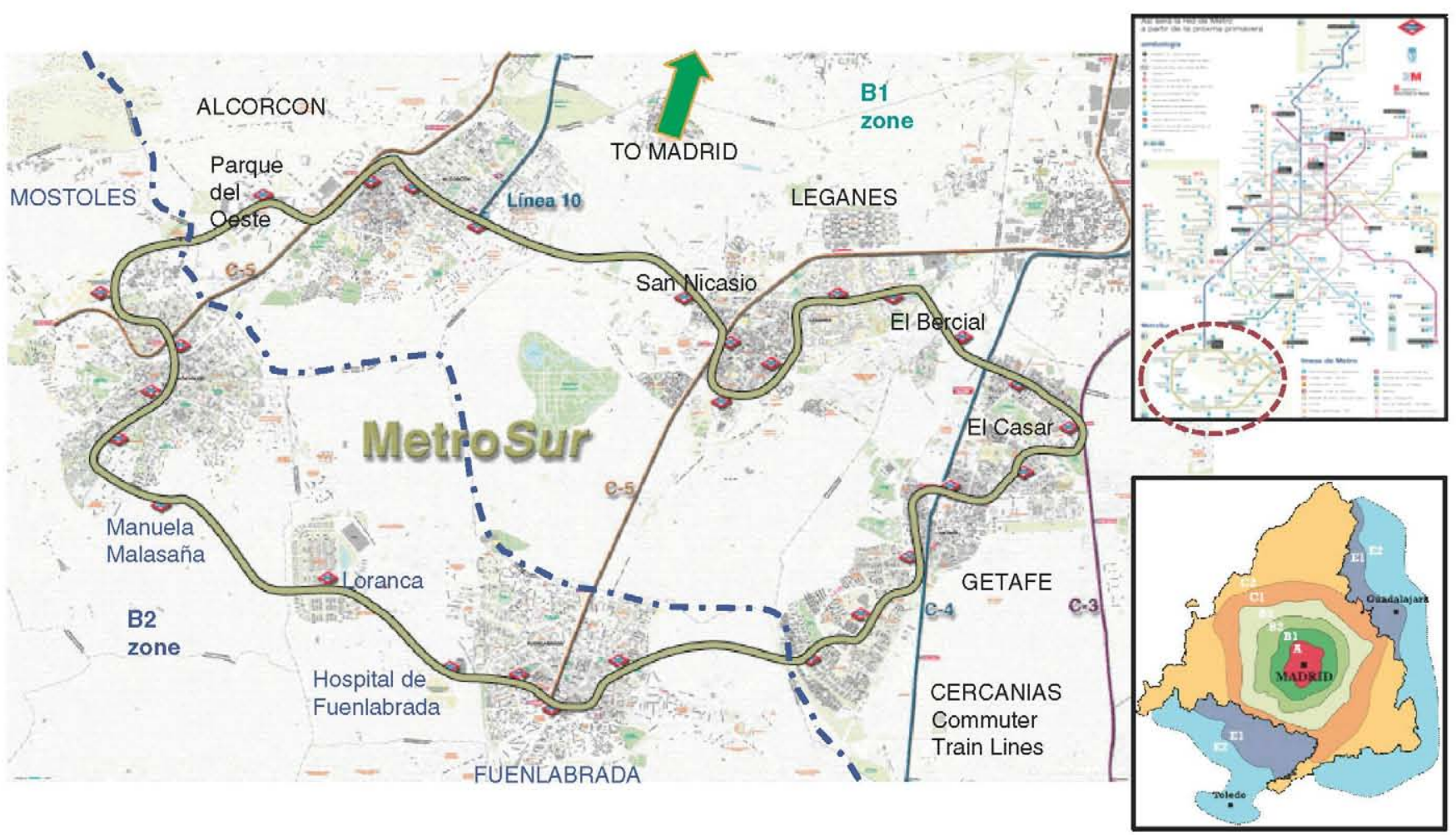

FIGURE 3 Map of Metrosur, its location within Madrid metro network, and Madrid transit fares. 


\section{HEDONIC MODELS AND SPATIAL ANALYSIS}

Hedonic regression analysis is popular for land market studies. Use of this technique is documented extensively in the literature. Hedonic models were popularized by Zvi Griliches in the early 1960s. It is said that Andrew Court proposed the first hedonic analysis in 1939 (25), although, according to Colwell and Dilmore, the origins of this methodology date back to the $1920 \mathrm{~s}$ (26). At first the focus was on consumer models. Rosen generalized use of the analysis for market equilibrium. The individual's utility was a function of the utility of the attributes that composed a product. Producer costs depended on the characteristics of that good (9). Equilibrium prices were determined so that buyers and sellers matched perfectly.

To obtain reliable results, the correct specification of the hedonic model is essential. There is no consensus in the literature on the variables that should be included in the model, basically because models depend on the information available. Three basic categories are generally accepted: structural characteristics, location attributes according to neighborhood, and accessibility characteristics, such as transport and other services. Typically, hedonic house price functions are expressed as

$P_{i}=\alpha_{i}+\sum_{j} \eta_{j i} S_{j i}+\sum_{l} \lambda_{i i} D_{l i}+\sum_{m} \phi_{m i} A_{m i}+\epsilon$

where

$i=$ observations available in the data set, as in any regression model;

$P=$ vector of selling prices;

$\alpha, \eta, \lambda$, and $\phi=$ correspondents to regression coefficients;

$S=$ vector of structural characteristics;

$D=$ vector of neighborhood attributes;

$A=$ vector that represents the accessibility attributes; and

$\epsilon=$ random error term vector

Its matrix notation is

$=\beta+\epsilon$

where

$=(n \times 1)$ vector of selling prices,

$=(n \times k)$ matrix with observations on structural or neighborhood or accessibility characteristics,

$\boldsymbol{\beta}=(k \times 1)$ vector of unknown regression coefficients, and

$\epsilon=$ assumed vector of independent and identically distributed (i.i.d.) error terms.

Traditional hedonic functions are linear econometric regression models, which are based on five assumptions: $(a)$ linearity, $(b)$ expected value of disturbance term is zero, $(c)$ disturbance terms are uniform and variance is uncorrelated, $(d)$ specification is correct, and $(e)$ no exact linear relationships exist within the model (27). The unknown parameter generally is estimated by OLS, such that

$\hat{\beta}=\left(X^{\prime} X\right)^{-1} X^{\prime} Y$

The OLS method generates the set of values of the parameters that minimizes the sum of squared residuals. Estimators should be consistent, unbiased, and efficient. Regression coefficient estimates provide a constant value for the entire sample.

In the real estate market, studies show no unique global market but rather market segments, in which locational and adjacent factors affect housing prices $(28)$. If the spatial nature of the data is not taken into account when modeling is done, errors such as spatial dependence (or spatial correlation) and spatial heterogeneity may be present in the analysis $(10,29-32)$. As a consequence, estimates may be inefficient, standard errors may be biased, and predicted values may be inaccurate $(10)$.

\section{Spatial Analysis}

Tests for spatial dependence in general are based on exploratory spatial data analysis. The set of techniques is designed to describe and visualize spatial distributions, to identify atypical points or spatial outliers, and to detect spatial pattern associations, such as clusters, which therefore suggest spatial autocorrelation or spatial heterogeneity (33).

Moran's I is a well-known local statistic to measure spatial dependency. Formally, it gives an indication on the degree of linear association between the vector $z_{t}$ of observed values and the vector $W_{i j} z_{i}$ of spatially weighted averages of neighboring values, called the spatially lagged vector. Values of $I$ that are larger than the expected value $E(1)=-1 /(n-1)$ indicate positive spatial autocorrelation, while values smaller than expected indicate negative spatial autocorrelation. Use of the statistic is based on a permutation approach, and it is assumed that, under the null hypothesis, each observed value could have occurred at all locations with equal likelihood. A high degree of spatial autocorrelation implies small differences at close distances and increasing differences at higher distances $(33,34)$. The statistic provides a way to express the coincidence of similar data in a certain place, or clustering. Further information about this statistic can be found in the work of Anselin $(11,35)$.

In the presence of spatial dependence, two approaches are available to analyze geographically distributed data: spatial econometrics and spatial statistics. Both are used increasingly in the analysis of property prices (36). Spatial econometrics may be used only if the data set analyzed is a disaggregated one (37). In this case, the most commonly known techniques are use of the spatial lag model (SLM) and the spatial error model (SEM) (38). Both models assume that there are either similarities or a strong relationship among properties located nearby.

The SLM is appropriate if the process is endogenous: in other words, if property prices are affected by the price of other properties in the neighborhood. This insight is used widely in assessment (e.g., consideration of comparative sales). To capture the endogenous component of the process, the model considers the spatially weighted average of house prices at each location of interest. Because the characteristics of the neighborhood influence the price of each house, a spatial multiplier in effect is captured. Technically, this effect is characterized by means of a new variable on the right-hand side of the equation that represents the interaction effect as a weighted average of neighboring observations (11). This model is suitable when the modeler wants to know the strength of this relationship and the true effect of the explanatory variables $(32,39)$. Usually, it is written in the matrix form as follows:

$$
=\rho+{ }_{i} \beta_{i}+\epsilon
$$

where

$=(n \times 1)$ vector of selling prices,

$=(n \times k)$ matrix with observations on structural or neighborhood characteristics,

$\boldsymbol{\beta}=(k \times 1)$ vector of unknown regression coefficients,

$\epsilon=$ assumed vector of independent and identically distributed (i.i.d.) error terms, and

$\rho=$ spatial autocorrelation parameter (scalar) 
The spatial lag, , introduces endogeneity to the model (because price becomes an exogenous and endogenous variable); therefore OLS estimators are inconsistent and biased. Maximum likelihood estimations, or other instrumental variables, are necessary to obtain consistent estimators $(11,40,41)$.

The SEM assumes that variables are omitted within the model that follows a spatial pattern, which leads to spatial autocorrelation within the error term. The lack therefore of an adequate analysis produces inefficient but unbiased and consistent estimators. Again, estimation must be based on the method of maximum likelihood or the generalized moments approach (42). It is generally written as

$$
={ }_{i} \boldsymbol{\beta}_{i}+\epsilon
$$

$\epsilon=\lambda \quad \epsilon+u$

where $\lambda$ is the spatial autoregressive coefficient and $u$ is assumed to be the vector of i.i.d. errors.

In both spatial analyses, is a matrix that accounts for interactions between locations, size $n$ (number of observations). It defines the relation among observations that are assumed to interact. It is a matrix that has positive $w_{i j}$ elements. Its diagonal elements are set to zero when $i$ and $j$ are neighbors, and are equal to zero otherwise. Usually its row elements are standardized such that the sum is equal to 1 . There are different ways to define the spatial weight matrices [e.g., through contiguity and distance, k-nearest neighbors $(11,29)$ ]. No formal guidance is available to choose the "correct" specification for spatial weight. To make a choice therefore is difficult work, which implies that many trials are needed.

\section{Housing Submarkets}

Spatial dependence and housing submarkets are related. The presence of submarkets implies that several housing units share similarities in price with their neighbors. Control of submarkets may reduce estimation errors (43). Geographical areas are natural submarkets, but they also can be specified by dummy variables, neighbors, postal codes, by estimation of a separate equation for each submarket, by adjustment of predicted values through use of the errors within each submarket, and by more sophisticated statistical techniques $(10,44)$. As Bourassa et al. noted, however, geographical subdivisions are easier to implement and perform better than spatial statistical methods $(44,45)$. Their findings show that even an OLS model, when it is specified correctly with submarket dummy variables, may obtain better results than geostatistical methods or lattice models and that these submarkets can be defined as geographical areas.

\section{Marginal Benefits}

Hedonic price function is an equilibrium price equation in which the price of house $i$ is defined as a function of the house characteristics. Theoretically, for each characteristic of interest, therefore, the firstorder condition defines the marginal willingness to pay for any characteristic that enters the utility function. Once the estimates for the coefficients are obtained, it is possible to estimate a prospective buyer's marginal willingness to pay for any characteristic that enters the utility function.
The above implies that, for OLS and SEM, the marginal benefits for the $i$ th variable are given by the following expression:

$\frac{\partial y}{\partial x_{i}^{\prime}}=\beta_{i} y$

The above expression is a differentiating equation with respect to the characteristic of interest. It can be interpreted as the price that it is accepted to pay for that characteristic.

In the case of SLM, the marginal benefit is given by

$\frac{\partial y}{\partial x_{i}^{\prime}}=\beta_{i}[-\rho]^{-1} y$

where is an identity matrix. According to Small and Steimetz, if property values are affected by pecuniary externalities, Equation 6 may be used for SLM, while Equation 7 should be used if there are technological externalities (46). Further information on marginal benefits can be found in the work of Anselin and Gallo (38), Won Kim et al. (41), Small and Steimetz (46), and Tsutsumi (47). According to Tsutsumi and Seya, the use of the spatial econometric approach to assess marginal benefits requires spatial tessellation data because it uses a spatial weight matrix (37).

\section{METHODS AND DATA}

As researchers have observed, hedonic models often exclude location variables [e.g., distance to relevant points such as the central business district (31)], which increases the probability of spatial error autocorrelation or heterogeneity. To minimize the problem, several variables were analyzed here, as shown in Table 1.

A Geographic Information System was used to calculate the real distance from each house to the closest amenity (e.g., metro station, shopping center) through the street network to the closest transport station. Many studies have agreed that Euclidean distance tends to overestimate the impacts on the population served by a transport facility $(48,49)$.

The data used in this paper were cross sectional. They were obtained from the real estate web page www.idealista.com (Spain's largest real estate website) because there were no official micro databases. A random day was chosen to select sales information from the site. The data were analyzed with the use of $\mathrm{GeoDa}(50)$ and Stata software. To minimize problems that could arise from unusual or influential data, outliers were controlled in advance. The easiest way to do so was to plot the data to get observations whose dependent-variable value was unusual (51). It was inferred that these cases were related to data entry errors, or that these observations were out of the market. Descriptive statistics on these observations are shown in Table 1.

\section{RESULTS}

Moran's I statistic for the dependent variable price (0.4094) showed that there was a positive spatial autocorrelation. The data set was analyzed first with an OLS approach, in which was observed the presence of spatial autocorrelation within its error term. OLS regression diagnostics demonstrated the presence of heteroscedasticity problems. A Box-Cox transformation therefore was used to verify if any transformation was needed. The results of the analysis suggested that no transformation was needed in the model. Several tests were 
TABLE 1 Variables Analyzed and Descriptive Statistics

\begin{tabular}{|c|c|c|c|c|c|}
\hline Variable & Description & Mean & SD & Min. & Max. \\
\hline \multicolumn{6}{|c|}{ Apartment Amenities } \\
\hline $\mathrm{C}$ & Constant & & & & \\
\hline price & House sale price $(€)$ & $227,896.3$ & $66,667.28$ & 99,000 & 600,000 \\
\hline $\mathrm{m}^{2}$ & House size (square meters) & 91.37 & 25.98 & 31 & 240 \\
\hline floor & Building floor level & 3.29 & 2.31 & 0 & 11 \\
\hline room & Rooms in apartment & 2.91 & 0.67 & 0 & 6 \\
\hline bathr & Bathrooms in apartment & 1.38 & 0.52 & 0 & 4 \\
\hline terr. & Terrace (square meters) & 3.75 & 8.06 & 0 & 120 \\
\hline basem & Dummy, 1 if the apartment has one & 0.31 & 0.46 & 0 & 1 \\
\hline $\mathrm{a} \_\mathrm{a}$ & Dummy, 1 if it includes air conditioning & 0.43 & 0.5 & 0 & 1 \\
\hline heating & Dummy, 0 if central, 1 if individual & 0.73 & 0.44 & 0 & 1 \\
\hline lift & Dummy, 1 if the building has elevator & 0.71 & 0.45 & 0 & 1 \\
\hline spool & If the urbanization has a swimming pool & 0.19 & 0.39 & 0 & 1 \\
\hline court & Dummy, 1 if it has tennis or basketball courts, gardens, or similar amenity & 0.42 & 0.49 & 0 & 1 \\
\hline parking & Number of places if they are included in the sales price & 0.24 & 0.45 & 0 & 2 \\
\hline \multicolumn{6}{|c|}{ Neighborhood Characteristics } \\
\hline pop & At each location its population $\left(\times 10^{6}\right)$ around $100 \mathrm{~m}$ (Euclidean distance) (pop.) & 503.92 & 622.03 & 0.31 & $3,267.26$ \\
\hline street & For each data point, its street around $500 \mathrm{~m}$ (Euclidean distance) (meters) & $1,096.48$ & 625.98 & 0 & $2,544.7$ \\
\hline school & Network distance to closest school-university (meters) & 374.94 & 270.51 & 0.01 & $5,375.38$ \\
\hline park_gym & Network distance to closest park or gym facilities (meters) & 543.32 & 490.54 & 0.01 & 5146.7 \\
\hline $\operatorname{sh\_ c}$ & Network distance to closest shopping center (meters) & 986.94 & 505.9 & 39.36 & $5,668.21$ \\
\hline hosp & Network distance to closest hospital (meters) & $1,011.96$ & 827.28 & 29.87 & $7,688.12$ \\
\hline pei & Per capita income per municipality (meters) & $13,811.96$ & 843.34 & 12,629 & 14,964 \\
\hline zone_B2 & Dummy, 1 if it is located at higher fare zone (Fuenlabrada, Mostoles) & 0.47 & 0.5 & 0 & 1 \\
\hline \multicolumn{6}{|c|}{ Transport Facilities } \\
\hline ms & Network distance to closest Metrosur station (meters) & 880.34 & 791.69 & 16.83 & $6,985.01$ \\
\hline cbd & Network distance to municipal central business district (meters) & $1,363.79$ & $1,124.84$ & 25 & $8,840.44$ \\
\hline cer & Network distance to commuter train station, Cercanias (meters) & $1,332.12$ & 991.01 & 92.42 & $6,897.83$ \\
\hline int & Network distance to closest interurban bus stop (meters) & 201.19 & 102.38 & 9.34 & 828.64 \\
\hline
\end{tabular}

Note: $\mathrm{SD}=$ standard deviation; $N=1,714$.

carried out to get better estimates. The results also showed that the best functional form was the linear one. Many studies also have suggested that this functional form is better to avoid biased estimations when transformed back to prices, to avoid nonobservance of spatial patterns, and for simplicity in the estimation of marginal prices (52).

Variables that were autocorrelated or not significant were taken out of the models. Afterward, the SEM and SLM were tested for different weight matrices. In both cases, the Moran's I statistic for residuals proved that spatial autocorrelation was controlled.

To improve the accuracy of results, some variables were used to control submarket effects, which was an alternative approach to the use of dummy variables $(10,44)$. In the analysis, the variables related to network distance were divided by income per capita as a way to relate each submarket to the hedonic specification.

Although $R$-squared cannot be compared across methods, it does give a reference when different versions of the same model are compared (i.e., when different weight matrices are used). It was possible nonetheless to compare the $\log$ likelihood and the Akaike information criterion across models. In this paper, only the final regression results are shown (Table 2)

The results suggested that, among other characteristics, a parking space within a residential building was valued highly, which was in the line with Jorda's finding that people in the case study area used cars to commute (24). The results also suggested that proximity to other households was not always an advantage when the desire was for privacy, or to avoid high rents, congestion, and other neighborhoodrelated problems. These findings were in accord with those of other researchers, such as Hoover and Giarratani (53).

The marginal value of $\mathrm{ms}$ (a continuous variable) indicated that each meter away from a Metrosur station had a distinct impact in each of the five municipalities. In other words, a house $1,000 \mathrm{~m}$ away from the closest Metrosur station cost between $2.18 \%$ and $3.18 \%$ less (given the municipality) than another one right next to the metro station, ceteris paribus. Figure 4 shows marginal values for both Metrosur and Cercanias (commuter rail) estimators. Cercanias had a higher impact than Metrosur. In other words, a house $1,000 \mathrm{~m}$ away from the closest Cercanias station cost between $3.38 \%$ and $5.17 \%$ less (given the municipality) than another one next to the station. As the models suggested, there were differences related to market segmentations, especially in zonal fares. The results suggested that to be located farther away from downtown Madrid carried an implicit price to be paid in higher time and economic costs.

For transfer stations (Metrosur and Cercanias), the value of both estimates should be added. This was the result of a better radial 
TABLE 2 Hedonic Model Results

\begin{tabular}{|c|c|c|c|}
\hline$R$-squared & .7591 & .7636 & .7650 \\
\hline Log likelihood & $-20,249.9$ & $-20,238.6$ & $-20,231.4$ \\
\hline $\begin{array}{l}\text { Akaike info } \\
\text { criterion }\end{array}$ & $40,527.8$ & $40,505.3$ & $40,492.8$ \\
\hline Variable & OLS & Spatial Error Model & Spatial Lag Model \\
\hline $\mathrm{C}$ & $\begin{array}{c}65,921.5600 * * \\
(3,975.429)\end{array}$ & $\begin{array}{c}68,564.3^{* *} \\
(4,265.663)\end{array}$ & $\begin{array}{c}42,584.1 * * \\
(5,484.156)\end{array}$ \\
\hline $\mathrm{m}^{2}$ & $\begin{array}{l}1,402.8910^{* *} \\
(42.63756)\end{array}$ & $\begin{array}{l}1,400.5710 * * \\
(43.10532)\end{array}$ & $\begin{array}{l}1,357.3570^{* * *} \\
(42.76402)\end{array}$ \\
\hline lift & $\begin{array}{c}19,696.7800^{* *} \\
(2,053.673)\end{array}$ & $\begin{array}{l}19,308.1700 * * \\
(2,083.496)\end{array}$ & $\begin{array}{c}18,207.8600 * * \\
(2,035.105)\end{array}$ \\
\hline bathr & $\begin{array}{l}17,679.4900^{* *} \\
(2,281.784)\end{array}$ & $\begin{array}{l}16,844.8700 * * \\
(2,293.362)\end{array}$ & $\begin{array}{l}15,889.0300^{* *} \\
(2,260.322)\end{array}$ \\
\hline heating & $\begin{array}{l}5,868.9630 * * \\
(1,855.498)\end{array}$ & $\begin{array}{c}5,214.945^{* *} \\
(1,889.629)\end{array}$ & $\begin{array}{l}5,113.653^{* *} \\
(1,827.406)\end{array}$ \\
\hline a_a & $\begin{array}{l}5,675.9520^{* *} \\
(1,628.007)\end{array}$ & $\begin{array}{l}5,603.8660 * * \\
(1,601.317)\end{array}$ & $\begin{array}{l}5,568.1830^{* *} \\
(1,601.539)\end{array}$ \\
\hline basem & $\begin{array}{l}8,831.1460^{* *} \\
(1,909.752)\end{array}$ & $\begin{array}{l}8,139.1700^{* *} \\
(1,907.114)\end{array}$ & $\begin{array}{l}8,132.9380^{* *} \\
(1,879.831)\end{array}$ \\
\hline spool & $\begin{array}{l}15,517.4800^{* *} \\
(2,313.651)\end{array}$ & $\begin{array}{l}15,329.5700 * * \\
(2,406.694)\end{array}$ & $\begin{array}{l}12,687.4200 * * \\
(2,324.918)\end{array}$ \\
\hline parking & $\begin{array}{c}24,322.4000 * * \\
(2,220.907)\end{array}$ & $\begin{array}{l}23,780.6500 * * \\
(2,252.612)\end{array}$ & $\begin{array}{c}22,977.9400 * * \\
(2,194.465)\end{array}$ \\
\hline zone_B2 & $\begin{array}{l}-31,553.56^{* *} \\
(1,899.969)\end{array}$ & $\begin{array}{c}-31,564.53 * * \\
(2,246.84)\end{array}$ & $\begin{array}{l}-28,817.85 * * \\
(1,924.455)\end{array}$ \\
\hline $\mathrm{ms} / \mathrm{pci}$ & $\begin{array}{c}-45,862.7400^{*} \\
(18,787.84)\end{array}$ & $\begin{array}{c}-45,912.3700 * \\
(22,044.94)\end{array}$ & $\begin{array}{c}-42,145.6000^{*} \\
(18,492.35)\end{array}$ \\
\hline cer/pci & $\begin{array}{l}-76,497.57^{* *} \\
(13,989.91)\end{array}$ & $\begin{array}{l}-74,584.5 * * \\
(16,442.75)\end{array}$ & $\begin{array}{c}-69,047.84 * * \\
(13,819.2)\end{array}$ \\
\hline hosp/pci & $\begin{array}{c}61,411.55^{* *} \\
(18,107.78)\end{array}$ & $\begin{array}{c}60,944.1 * * \\
(21,288.32)\end{array}$ & $\begin{array}{c}47,469.47 * * \\
(17,963.27)\end{array}$ \\
\hline pop & $\begin{array}{l}-0.1244867^{* *} \\
(0.04346661)\end{array}$ & $\begin{array}{l}-0.1474505 * * \\
(0.05079898)\end{array}$ & $\begin{array}{l}-0.07174224 \\
(0.04380104)\end{array}$ \\
\hline lambda & & $\begin{array}{l}0.1827401 * * \\
(0.0379598)\end{array}$ & \\
\hline $\mathrm{W}$ price & & & $\begin{array}{c}0.1338048 * * \\
(0.02199083)\end{array}$ \\
\hline
\end{tabular}

NoтE: Estimated coefficients are presented in euros; observations $=1,714$. ${ }^{*} p<.05 ; * * p<.01$

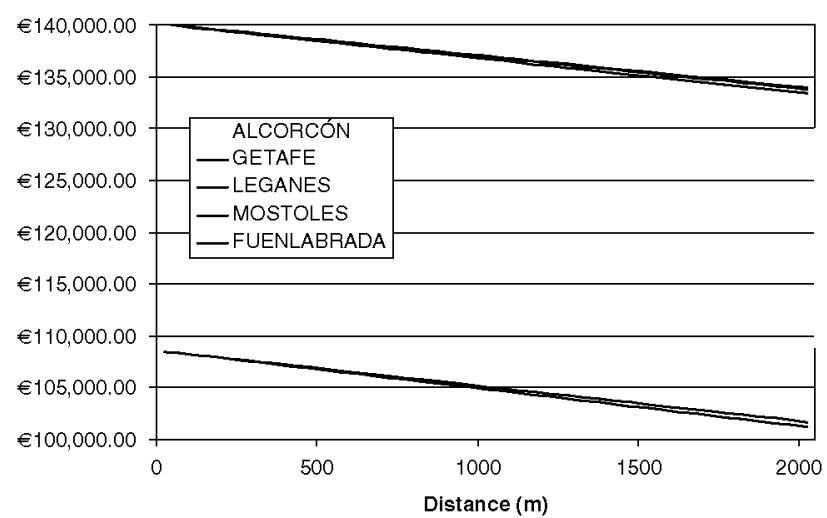

(a)

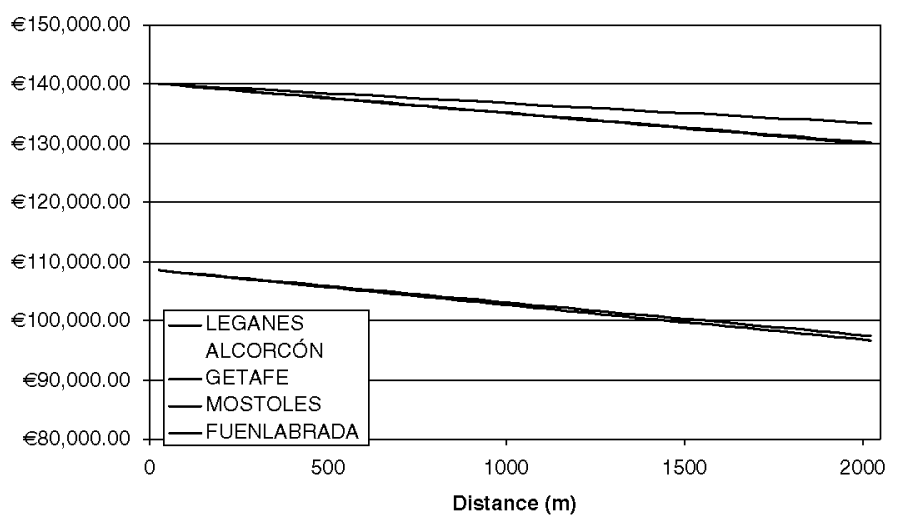

()

FIGURE 4 Impact on value of house related to its distance from (a) Metrosur and $(b)$ Cercanias stations. 
and circular accessibility. Thus transfer stations appeared to have become valued the most, ceteris paribus, among all stations within the municipalities studied.

\section{CONCLUDING REMARKS AND DISCUSSION}

This paper presents an empirical analysis of the real estate market in the south of Madrid to assess the economic benefits of a recent metro line infrastructure. The results of the study indicated that better accessibility to Metrosur stations had a positive impact on real estate values and that the effect was particularly marked in cases in which a house was for sale.

To avoid a discussion of pecuniary impact $(46,47)$, the results of the three models (OLS, SLM, and SEM), are presented, which were similar. According to Tsutsumi and Seya, some limitations exist in the spatial econometric approach to benefit evaluation because it uses a spatial weight matrix. Thus those parameters would be valid only for the given spatial weight matrix (54). In an empirical analysis, however, it is possible to observe that results in all cases are quite similar. It was concluded that the estimates were similar because the models accounted for housing submarkets and use was made of a detailed data set. This conclusion was consistent with Bourassa et al. $(44,45)$. Even without a spatial analysis, if submarkets are well controlled (in this case, market segmentations were accounted for by means of geographic boundaries and the transit zonal fare), and accurate information is used, OLS is a practical method that provides congruent estimates.

The results successfully appraised the benefit that an urban mass transport infrastructure produces in house prices. The distance to Cercanias stations, however, was economically more important that the distance to the Metrosur stations. This result may be explained by the fact that the commuter rail lines took people directly to downtown Madrid through a radial trip and therefore in less time. Metrosur stations took people to other municipalities or to the closest metro and commuter transfer station. Apparently, those commuters that used public transportation preferred transit that took them to Madrid (i.e., Cercanias, commuter rail lines).

The municipalities that benefited the least from Metrosur had a more expensive transit fare (Zone B2), were located farthest away from the city of Madrid, and had the smallest per capita income. These observations revealed the trade-off between lower prices for housing and higher costs in time and transport fares. In other words, the results showed a higher willingness to pay for more accessible locations, especially in the municipalities closest to Madrid

Sometimes fare policies are intended to limit the location of people far from the city core. From the perspective of social equity, however, continued research might be needed to verify whether this policy fulfills the transportation goals at the local and regional levels, or whether it limits the integration of outlying populations with the whole region. Researchers such as Cervero have found that transit fares have different effects in areas with low population density and suburban settings: people are more reluctant to take public transport if they have a car available and at the same time are prone to accept an increase in the ticket fare when they make radial trips, which in this case would mean a higher appraisal of Cercanias than Metrosur (55). The results with regard to parking spaces also suggested that people in this area relied on cars to commute, which was in line with the findings of Jordá (24). The appraised value of transfer stations increased in both modes, which related to an increase of vertical and horizontal accessibility. Further studies should focus on the advantages that populations perceive in these stations.
If the reason to travel from one point to another many times is to engage in economic activities, such as shopping and working, the question that arises is if the increase in economic activities within the five municipalities is sufficient to cause people to increase their use of Metrosur around the region rather than go back and forth to the city of Madrid. A better job-housing balance would increase the use of Metrosur and therefore its economic appreciation. Rather than foster integration across all the municipalities, Fuenlabrada and Mostoles might pursue a separate, less accelerated track in the quest for more balanced growth.

Urban planning and design play important roles to foster the use of public transport. A dense street network that puts public transit within easy reach encourages its use. A look at new urban development in the zones that were studied, however, showed that they were caroriented. Examples, such as the A-B-C policy in the Netherlands, should be borne in mind, which have succeeded in taking advantage of areas close to transit stations. Not only is it important to have a public transit station near a neighborhood but also a combination of other factors in place, such as the optimization of resources and political agreements that foster the use of public transport.

Finally, another application of these models for urban studies might be value capture. Although the subject of much discussion, it is a complicated concept to put it into practice. In Spain, certain fiscal mechanisms already are in place that relate to property prices (56). The Urban Land Value Increase Tax (commonly known as Impuesto sobre Plusvalias) is one of them. Its main problem is that Spanish taxes are not earmarked. None of the benefits triggered by the transport infrastructure are returned to the Madrid regional transport authority, because it is the municipality that levies the rate of the tax and is the one that collects it. These kinds of models open the possibility to account for real increases in land value and any transport impacts in order to transfer to the transport authority the percentage increase produced by the public transportation system. Such an approach would lead to more economic resources to maintain the public transport infrastructure with higher social acceptability, especially during periods of budgetary constraints.

\section{ACKNOWLEDGMENTS}

Financial support from the Ministry of Science and Innovation of Spain is gratefully acknowledged. The authors thank Javier Gutierrez and Juan Carlos Garcia of the Department of Human Geography of the Universidad Complutense de Madrid for information that helped to carry out this research.

\section{REFERENCES}

1. Banister, D., and J. Berechman. Transport Investment and Economic Development. Routledge, New York, 2000

2. Mas, M., and J. Maudos. Infraestructuras y Crecimiento Regional En España Diez Años Después. In Competitividad Regional en la Union Europea Ampliada (José Villaverde Castro, coord.), Instituto de Estudios Fiscales, Madrid, 2004, pp. 143-168.

3. Boarnet, M. G. Conducting Impact Evaluations in Urban Transport. Doing Impact Evaluation Series 5. World Bank, Washington, D.C., 2006.

4. Fujita, M. Urban Economic Theory: Land Use and City Size. Cambridge University Press, United Kingdom, 1989

5. Cambridge Systematics Inc. TCRP Report 35: Economic Impact Analysis of Transit Investment: Guidebook for Practitioners, TRB, National Research Council, Washington, D.C., 1998.

6. Maoh, H. F., M. Koronios, and P. Kanaroglou. Exploring the Land Development Process and Its Impact on Urban Form in Hamilton, Ontario. The Canadian Geographer, Vol. 54, No. 1, 2010, pp. 68-86.

7. Bailey, M. J., R. F. Muth, and H. O. Nourse. A Regression Method for Real Estate Price Index Construction. Journal of the American Statistical Association, Vol. 58, No. 304, 1963, pp. 933-942. 
8. Sommervoll, D. E. Temporal Aggregation in Repeated Sales Models Journal of Real Estate Finance and Economics, Vol. 33, No. 2, 2006, pp. $151-165$.

9. Rosen, S. Hedonic Prices and Implicit Markets: Product Differentiation in Pure Competition. Journal of Political Economy, Vol. 82, No. 1, 1974, p. 34.

10. Dubin, R. A. Estimation of Regression Coefficients in the Presence of Spatially Autocorrelated Error Terms. The Review of Economics and Statistics, Vol. 70, No. 3, 1988, pp. 466-474.

11. Anselin, L. Spatial Econometrics: Methods and Models. Springer-Verlag, Berlin, 1988.

12. Duncan, M. Comparing Rail Transit Capitalization Benefits for SingleFamily and Condominium Units in San Diego, California. In Transportation Research Record: Journal of the Transportation Research Board, No. 2067, Transportation Research Board of the National Academies, Washington, D.C., 2008, pp. 120-130.

13. Yoo, E. H., and P. C. Kyriakidis. Area-to-Point Kriging in Spatial Hedonic Pricing Models. Journal of Geographical Systems, Vol. 11, No. 4, 2009, pp. 381-406.

14. Perk, V., M. Mugharble, and M. Catala. Impacts of Bus Rapid Trans (BRT) Stations on Surrounding Single-Family Home Values: Study of Pittsburgh's East Busway. Transportation Research, Vol. 7, Transit, Volume II, 2010.

15. Andersson, D. E., O. F. Shyr, and J. Fu. Does High-Speed Rail Accessibility Influence Residential Property Prices? Hedonic Estimates from Southern Taiwan. Journal of Transport Geography, Vol. 18, 2008

16. Habib, M. A., and E. J. Miller. Influence of Transportation Access and Market Dynamics on Property Values: Multilevel Spatiotemporal Models of Housing Price. In Transportation Research Record: Journal of the Transportation Research Board, No. 2076, Transportation Research Board of the National Academies, Washington, D.C., 2008, pp. 183-191.

17. Martínez, L. M., and J. M. Viegas. Effects of Transportation Accessibility on Residential Property Values: Hedonic Price Model in Lisbon, Portugal, Metropolitan Area. In Transportation Research Record: Journal of the Transportation Research Board, No. 2115, Transportation Research Board of the National Academies, Washington, D.C., 2009, pp. 127-137.

18. Du, H., and C. Mulley. Relationship Between Transport Accessibility and Land Value: Local Model Approach with Geographically Weighted Regression. In Transportation Research Record: Journal of the Transportation Research Board, No. 1977, Transportation Research Board of the National Academies, Washington, D.C., 2006, pp. 197-205.

19. Militino, A., M. Ugarte, and L. García-Reinaldos. Alternative Models for Describing Spatial Dependence Among Dwelling Selling Prices. Journal of Real Estate Finance and Economics, Vol. 29, No. 2, 2004 pp. 193-209.

20. Montero-Lorenzo, J. M., B. Larraz-Iribas, and A. Páez. Estimating Commercial Property Prices: An Application of Cokriging with Housing Prices as Ancillary Information. Journal of Geographical Systems, 2009, pp. 1-19.

21. Bengochea-Morancho, A. A Hedonic Valuation of Urban Green Areas Landscape and Urban Planning, Vol. 66, No. 1, 2003, pp. 35-41.

22. Instituto Nacional de Estadística. National Statistics Institute. http://www. ine.es. Accessed June 15, 2010.

23. Melis, M., et al. Metrosur. Metro de Madrid, 2003

24. Jordá, P. Assessment of Time Use Constraints in Multimodal Trips. Madrid Case Study. Young Researchers Seminar, Torino, Italy, 2009.

25. Goodman, A. C. Andrew Court and the Invention of Hedonic Price Analysis. Journal of Urban Economics, Vol. 44, No. 2, 1998, pp. 291-298.

26. Colwell, P. F., and G. Dilmore. Who Was First? An Examination of an Early Hedonic Study. LandEconomics, Vol. 75, No. 4, 1999, pp. 620-626.

27. Kennedy, P. A Guide to Econometrics. MIT Press, Cambridge, Mass., 2003

28. Can, A. Specification and Estimation of Hedonic Housing Price Models. Regional Science and Urban Economics, Vol. 22, No. 3, 1992, pp. 453-474.

29. Dubin, R. A. Spatial Autocorrelation: A Primer. Journal of Housing Economics, Vol. 7, No. 4, 1998, pp. 304-327.

30. Can, A., and I. Megbolugbe. Spatial Dependence and House Price Index Construction. Journal of Real Estate Finance and Economics, Vol. 14, No. 1, 1997, pp. 203-222

31. Paez, A., T. Uchida, and K. Miyamoto. Spatial Association and Heterogeneity Issues in Land Price Models. Urban Studies, Vol. 38, No. 9, 2001, p. 1493
32. Won Kim, C., T. T. Phipps, and L. Anselin. Measuring the Benefits of Air Quality Improvement: A Spatial Hedonic Approach. Journal of Environmental Economics and Management, Vol. 45, No. 1, 2003 , pp. 24-39.

33. Anselin, L. Exploratory Spatial Data Analysis in a Geocomputational Environment. John Wiley and Sons Inc., New York, 1998.

34. Cressie, N. Statistics for Spatial Data. John Wiley and Sons, Inc., New York, 1991.

35. Anselin, L. Local Indicators of Spatial Association-LISA. Geographical Analysis, Vol. 27, No. 2, 1995, pp. 93-115.

36. Páez, A. Recent Research in Spatial Real Estate Hedonic Analysis. Journal of Geographical Systems, Vol. 11, No. 4, 2009, p. 311.

37. Tsutsumi, M., and H. Seya. Hedonic Approaches Based on Spatial Econometrics and Spatial Statistics: Application to Evaluation of Project Benefits. Journal of Geographical Systems, Vol. 11, No. 4, 2009, pp. 357-380.

38. Anselin, L., and J. L. Gallo. Interpolation of Air Quality Measures in Hedonic House Price Models: Spatial Aspects. Spatial Economic Analysis, Vol. 1, No. 1, 2006, pp. 31-52.

39. Cho, S. H., D. M. Lambert, R. K. Roberts, and S. G. Kim. Demand for Open Space and Urban Sprawl: The Case of Knox County, Tennessee. Progress in Spatial Analysis: Methods and Applications, 2010, p. 171.

40. Ord, K. Estimation Methods for Models of Spatial Interaction. Journal of the American Statistical Association, Vol. 70, No. 349, 1975, pp. 120-126.

41. Won Kim, C., T. T. Phipps, and L. Anselin. Measuring the Benefits of Air Quality Improvement: A Spatial Hedonic Approach. Journal of Environmental Economics and Management, Vol. 45, No. 1, 2003, pp. 24-39.

42. Ord, K. Estimation Methods for Models of Spatial Interaction. Journal of the American Statistical Association, Vol. 70, No. 349, 1975, pp. 120-126.

43. Redfearn, C. L. How Informative Are Average Effects? Hedonic Regression and Amenity Capitalization in Complex Urban Housing Markets. Regional Science and Urban Economics, Vol. 39, No. 3, 2009, pp. 297-306.

44. Bourassa, S. C., C. Cantoni, and M. Hoesli. Spatial Dependence, Housing Submarkets, and House Price Prediction. Journal of Real Estate Finance and Economics, Vol. 35, No. 2, 2007, p. 143

45. Bourassa, S. C., M. Hoesli, and V. S. Peng. Do Housing Submarkets Really Matter? Journal of Housing Economics, Vol. 12, No. 1, 2003 , p. 12.

46. Small, K. A., and S. Steimetz. Spatial Hedonics and the Willingness to Pay for Residential Amenities. Economics Working Paper, 2006, p. 31.

47. Tsutsumi, M. Measuring the Impact of Large-Scale Transportation Projects on Land Price Using Spatial Statistical Models. Papers in Regional Science, Vol. 87, No. 3, 2008, p. 385

48. Hsiao, S., J. Lu, J. Sterling, and M. Weatherford. Use of Geographic Information System for Analysis of Transit Pedestrian Access. In Transportation Research Record 1604, TRB, National Research Council, Washington, D.C., 1997, pp. 50-59.

49. Gutiérrez, J., and J. C. García-Palomares. Distance-Measure Impacts on the Calculation of Transport Service Areas using GIS. Environment and Planning B: Planning and Design, Vol. 35, No. 3, 2008, pp. 480-503.

50. Anselin, L., I. Syabri, and Y. Kho. GeoDa: An Introduction to Spatial Data Analysis. Geographical Analysis, Vol. 38, No. 1, 2006, pp. 5-22.

51. UCLA: Academic Technology Services, Statistical Consulting Group Regression with Stata Web Book. Regression Diagnostics. www.ats.ucla edu/stat/Stata/webbooks/reg/chapter2/statareg2.htm. Accessed Jan. 20 2010.

52. Long, F., A. Páez, and S. Farber. Spatial Effects in Hedonic Price Estimation: A Case Study in the City of Toronto. Centre for Spatial Analysis, McMaster University, Hamilton, Ontario, Canada, 2007.

53. Hoover, E. M., and F. Giarratani. An Introduction to Regional Economics. Knopf, New York, 1971.

54. Tsutsumi, M., and H. Seya. Hedonic Approaches Based on Spatial Econometrics and Spatial Statistics: Application to Evaluation of Project Benefits. Journal of Geographical Systems, Vol. 11, No. 4, 2009 , pp. 357-380.

55. Cervero, R. Transit Pricing Research. Transportation, Vol. 17, No. 2, 1990, p. 117.

56. Mejia Dorantes, L., and J. M. Vassallo Magro. Financing urban transport through value capture. In Proceedings of the 9 th Highway and Urban Environment Symposium, Madrid, 2008. Springer, Dordrecht, Netherlands, 2010, pp. 15-21.

The Transportation and Land Development Committee peer-reviewed this paper. 